\title{
IZOBRAŽEVALNE POTREBE PONUDNIKOV ZASEBNIH TURISTIČNIH NASTANITEV V SLOVENIJI
}

Gregor Balažič, univ. dipl. geog.

Univerza na Primorskem, Fakulteta za turistične študije - Turistica

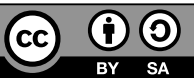

Obala I la, SI-6320 Portorož

e-pošta: gregor.balazic@fts.upr.si

Izvirni znanstveni članek

COBISS 1.01

DOI: $10.4312 /$ dela.47.107-126

\section{Izvleček}

V okviru projekta ROOMS to VET je bila opravljena raziskava med zasebnimi ponudniki turističnih nastanitev v Sloveniji. Z izvedenskimi intervjuji smo identificirali splošne probleme in potrebe na področju njihovega izobraževanja. Rezultati kažejo, da je najbolj problematično poznavanje zapletene zakonodaje. Ponudniki se zavedajo pomembnosti izobraževanja in izpostavljajo pomanjkanje organiziranih izobraževanj, nepovezanost turističnih ponudnikov in pomanjkljiva znanja na področju obvladovanja različnih spletnih orodij.

Ključne besede: Turizem, Slovenija, ponudniki zasebnih turističnih nastanitev, izobraževanje

\section{EDUCATIONAL NEEDS OF SMALL HOTEL AND NON-HOTEL PROVIDERS IN SLOVENIA}

\begin{abstract}
The ROOMS to VET project has carried out a survey among private providers of tourist accommodation in Slovenia. Through interviews were identified general problems and needs in the field of education. The results show that the most problematic is legislation, in that the providers are burdened with the necessity of knowing all the fine points of labyrinthine legislation. Providers are aware of the importance of education and underline the lack of organized education, the lack of links between tourism providers and insufficient knowledge in the usage of various online tools.
\end{abstract}

Keywords: Tourism, Slovenia, private providers of tourist accommodation, education 


\section{UVOD}

Evropa je vodilna turistična destinacija na svetu z najvišjo gostoto in raznolikostjo turističnih znamenitosti (Council of the European Union, 2004). Po Eurostatu je predstavljal delež zasebnih turističnih nastanitev v Evropi v letu 2009 kar 13 \% vseh turističnih nastanitev (Eurostat, 2017). Mnogi turisti se danes odločijo za zasebne sobe, apartmaje ali stanovanja. Pri tem igra pomembno vlogo več dejavnikov, kot so iskanje svobode, zasebnost, stik z naravo, lokalnimi podjetji in kulturo ter nizki stroški preživljanja dopusta itd.

Statistični podatki kažejo, da se mnogi turisti odločajo za bivanje v zasebnih turističnih nastanitvah tudi v Sloveniji. Med zasebne turistične nastanitve (ZNZ) spadajo po opredelitvi Statističnega urada Republike Slovenije zasebne sobe, apartmaji in hiše (SURS, 2017a). Po podatkih SURS-a (2016a) je bilo leta 2014 v Sloveniji v zasebnih sobah registriranih 13.988 stalnih ležišč, v katerih so zabeležili 606.094 nočitev, kar predstavlja $6,3 \%$ od skupnega števila vseh nočitev v vseh nastanitvenih obratih, ki je znašalo 9.590.642 nočitev (SURS, 2016b). Vsebinsko med ZNZ uvrščamo tudi turistične kmetije z nastanitvijo in male hotele. Po opredelitvi Statističnega urada Republike Slovenije turistične kmetije z nastanitvijo ne sodijo med ZNZ, malih hotelov pa kot samostojno statistično kategorijo urad ne vodi, zato podatki niso na voljo. V letu 2014 je bilo na turističnih kmetijah z nastanitvijo registriranih 4.446 stalnih ležišč, v katerih so zabeležili 124.086 nočitev (SURS, 2016a, 2016b).

Kategorizacijo in način oddajanja turističnih sob v Sloveniji urejata Zakon o gostinstvu (2007) in Pravilnik o kategorizaciji nastanitvenih obratov (2008-2009). Nastanitveni obrat, ki se kategorizira, mora predhodno izpolnjevati vse splošne in posebne pogoje, predpisane s Pravilnikom o minimalnih tehničnih pogojih in o minimalnem obsegu storitev za opravljanje gostinske dejavnosti (2000-2008). Zasebne sobe je v Sloveniji torej možno legalno oddajati na dva načina, po že omenjenem Zakonu o gostinstvu (2007) in po Stanovanjskem zakonu (2003).

V okviru evropskega projekta ROOMS to VET, v katerem so sodelovale države partnerice Hrvaška, Ciper, Grčija, Slovenija in Španija in katerega cilj je ohraniti in povečati konkurenčnost evropskega turističnega gospodarstva s podporo izpopolnjevanju in profesionalizaciji turističnih storitev, smo izvedli raziskavo potreb po izobraževanju med ponudniki zasebnih turističnih nastanitev (sobodajalci) v Sloveniji, kar predstavlja osnovo za razvoj učnih gradiv ter nastanek brezplačne spletne platforme za usposabljanje. Ker področje oddajanja zasebnih turističnih nastanitev urejata dva zakona in je v Sloveniji prisotno tudi neregistrirano oddajanje nastanitev ter predstavlja področje izobraževanja enega od pomembnih pristopov za spodbujanje turizma, smo z izvedenskimi intervjuji podrobneje raziskali problematiko, identificirali probleme in nanje opozorili. Izpostavili smo omejitve in priložnosti ter nakazali rešitve za učinkovitejši in bolj reguliran razvoj sobodajalstva. Z raziskavo smo želeli dobiti odgovor na osnovno vprašanje, ki se je nanašalo na splošne probleme, ki jih zaznavajo sobodajalci, in specifična vprašanja, ki se nanašajo na potrebe po usposabljanju in izobraževanju. Ciljna skupina so bili s turizmom povezani deležniki iz lokalnih, regionalnih in nacionalnih združenj ter organizacij. Sodelujoči v raziskavi so bili pozvani, da izpostavijo ključne potrebe po izobraževanju in 
usposabljanju. V ospredje smo postavili področje usposabljanja oziroma izobraževanja, pogostost, način in obliko. Iz tega smo izpeljali pet raziskovalnih vprašanj:

1. Kateri dejavniki so najbolj kritični na področju sobodajalstva v Sloveniji in zakaj?

2. Ali potrebujejo sobodajalci visoko stopnjo znanja/vedenja o vodenju turistične dejavnosti?

3. Katera učna področja bi sobodajalcem olajšala vsakodnevno delo?

4. Kateri so najprimernejši načini za izobraževanje in izpopolnjevanje sobodajalcev?

5. Katere zanimive prakse poklicnega izobraževanja in usposabljanja za sobodajalce poznajo in katera oblika usposabljanja ali učenja bo sobodajalcem najbolj pomagala prilagoditi se na prihajajoče spremembe?

\section{PROBLEMATIKA ZASEBNIHTURISTIČNIH NASTANITEV IN IZOBRAŽEVANJA}

Na področju oddajanja zasebnih turističnih nastanitev je zaznati številne probleme. Jurinčič (2009) je ocenjeval na podlagi sorazmerno povečane porabe vode, da je bilo neprijavljenih/neregistriranih turistov in obiskovalcev v Slovenski Istri 11.250 (oziroma $50 \%$ prijavljenih). Pri tem so med neregistrirane turiste in obiskovalce, ki so porabniki vode, šteti dnevni obiskovalci/kopalci (tuši in sanitarije), neregistrirani turisti v zasebnih sobah, počitniških domovih in drugih pomožnih/nehotelskih nastanitvenih zmogljivostih ter sorodniki, znanci in imetniki, ki prebivajo v počitniških stanovanjih. Z izmikanjem plačevanju turistične takse in drugih dajatev lokalni skupnosti in državi neregistrirani turisti in sobodajalci ne prispevajo ničesar k izgradnji prepotrebne komunalne in prometne infrastrukture, ki je v sezoni preobremenjena. Podobno velja za zgornje Posočje (Močnik, 2014). To pomembno vpliva tudi na slabšo kakovost turističnih storitev, ki jo registrirani turisti zaznajo kot gnečo na cestah in plažah, omejevanje porabe vode v sušnih obdobjih za tuširanje, pomanjkanje parkirnih mest idr. Zato menimo, da je treba v okviru izobraževalnih programov za obstoječe in potencialne sobodajalce opozoriti na posledice nelegalnega oddajanja zasebnih namestitvenih zmogljivosti. Posledično neregistrirani sobodajalci niso uvrščeni na spletne strani lokalnih turističnih organizacij in niso deležni izobraževanj, ki jih organizirajo zbornice, društva, občine in Slovenska turistična organizacija (STO).

Pomembno vlogo pri trženju ZNZ imajo lokalne, regionalne (Alford, 1998) in nacionalne turistične organizacije. S pojavom nizkocenovnih letalskih prevoznikov in medmrežja ter socialnih omrežij so se odprle možnosti za globalno trženje ZNZ, tudi tistih, ki niso registrirane oziroma ne plačujejo davkov lokalni skupnosti in državi. To predstavlja poslovno priložnost, da se z oddajanjem zasebnih sob lahko ukvarja kdorkoli, tudi brez ustrezne izobrazbe in strokovnih znanj, kar pa nedvomno vpliva na kakovost storitve in njeno nekonkurenčnost. Večje število zasebnih sob nižjih kategorij brez dodatne turistične ponudbe in osebnega stika z najemnikom vpliva dolgoročno na nižanje cen turističnih storitev in upad slovesa destinacije. Mednarodne izkušnje kažejo, da ZNZ višje kakovosti z izobraženimi lastniki in managerji, ki so povezani z lokalnim okoljem 
in turističnimi ponudniki na destinaciji, uspešno konkurirajo uveljavljenim obalnim destinacijam z masovnim hotelskim turizmom (Hernández, Suárez-Vega, Santana-Jiménez, 2016).

Turistične kmetije z nastanitvijo so v Sloveniji pomemben dejavnik ponudbe ZNZ. Organizirano nastopajo na trgu od leta 1992 z ustanovitvijo Zadružne turistične agencije Vas in izdajo prvega tiskanega kataloga (Murn, Kocbek, Krašovec, 1992). Pri tem so vseskozi potekala izobraževanja s strani KGZS (Kmetijsko gospodarska zbornica Slovenije) in kasneje tudi STO ter lokalnih turističnih organizacij. Predstavljajo tudi najbolj okoljsko ozaveščen segment med ponudniki vseh nastanitvenih zmogljivosti v Sloveniji. Kar četrtina turističnih kmetij z nastanitvijo je opremljena z ekološkim znakom kakovosti oz. so vpisane v kontrolo ekološkega kmetovanja (Jurinčič, Balažič, 2011). Kljub neugodni starostni strukturi na kmetijah, povprečna starost slovenskega kmeta je 57 let, velja, da imajo kmetje nekoliko višjo izobrazbo od povprečja držav EU (SURS, 2017b). Dejavnost turističnih kmetij je za slovensko podeželje zelo pomembna, saj turizem omogoča zaposlovanje, ohranjanje kmetijske dejavnosti, vaških skupnosti in kulturne pokrajine ter prispeva $\mathrm{k}$ dodani vrednosti kmetijskih pridelkov in izdelkov (Cigale, Lampič, Potočnik Slavič, 2013). Po prenehanju delovanja Zadružne turistične agencije Vas so turistične kmetije samostojno in ponekod preko lokalnih turističnih organizacij tržile svoje zmogljivosti. Leta 1997 so ustanovile Združenje turističnih kmetij Slovenije, ki v sodelovanju z lokalnimi in regionalnimi turističnimi organizacijami ter STO-jem skrbi za skupno promocijo in razvoj. Nasploh velja, da je turizem lahko pomemben dejavnik razvoja na podeželju, ki je pogosto razvojno nekoliko zapostavljeno. Pri tem imajo danes pomembno vlogo tudi informacijsko-komunikacijske tehnologije (IKT). Te omogočajo boljšo prepoznavnost, vključevanje na turistični zemljevid in trženje izdelkov ter storitev. Zaradi razlik v usvojitvi znanj in veščin predstavljajo nekaterim uporabnikom priložnost, drugim pa oviro (Planinc, Planinc, Sedmak, 2015).

Zasebni sobodajalci se povezujejo v lokalna turistična društva in svoje zmogljivosti tržijo preko turističnoinformacijskih centrov in birojev (Debeljak, 2009), turističnih agencij in preko spleta (Booking.com, Airbnb, STO-jeva stran, lastna spletna stran, Facebook, Twitter, Instagram idr.).

Formalna izobraževanja za lastnike, managerje in zaposlene v ZNZ izvajajo na poklicni/srednješolski in visokošolski/univerzitetni stopnji različne institucije: srednje gostinske in turistične šole v Izoli, Radovljici, Ljubljani, Radencih, Celju, Mariboru in Novem mestu, višje gostinske in turistične šole v Mariboru, na Bledu, Ljubljani in Novem mestu ter visoke šole in fakultete v Portorožu, na Bledu, Ljubljani, Mariboru in Brežicah. Neformalna poklicna in strokovna izobraževanja pa organizirajo gostinsko turistične zbornice in združenja, lokalne in regionalne turistične organizacije ter STO. Izvajajo jih za specifično področje izobraževanja usposobljeni strokovnjaki z izkušnjami iz prakse. Srednje šole izvajajo programe izobraževanja v učilnicah, medtem ko višje in visoke šole ter fakultete poleg klasične izvedbe $\mathrm{v}$ učilnici izvajajo tudi e-oblike učenja s pomočjo aplikacije Moodle.

Izobraževanje je pomembno tudi za spodbujanje podjetniške dejavnosti, kar je prepoznala tudi Evropska komisija in sprejela nekaj ukrepov za spodbujanje podjetniškega 
izobraževanja. Med drugim je izdala Akcijski načrt za podjetništvo 2020, s ciljem spodbujanja podjetniškega potenciala (European Commission, 2013). Omenjeni programski načrt se osredotoča tudi na področje turizma, kjer podjetniki zlasti na podeželju izpostavljajo pomanjkanje znanja s področja IKT, financ in računovodstva ter dodatnih znanj, ki bi pripomogla $\mathrm{k}$ uspešnejšemu mreženju, prodoru na nove trge, uporabi novih oblik trženja in uspešnemu pridobivanju sredstev iz Evropske unije (Planinc in sod., 2016).

\section{METODE}

Odgovore na zastavljena vprašanja smo pridobili s pomočjo izvedenskih ali ekspertnih intervjujev. Za ekspertni intervju je značilno, da se ta prične s peščico vprašanj, ki pokrivajo zelo splošne teme, pri tem pa sogovornik podaja daljše odgovore, pri čemer prihaja do izmenjave stališč intervjuvanega z interjuvancem (Schensul 2008). Za potrebe raziskave smo uporabili nekatere značilnosti strukturiranega in polstrukturiranega intervjuja. Tako so intervjuvani odgovarjali znotraj zastavljenega vsebinskega ali tematskega okvira na vprašanja zaprtega (eksplicitnega ali implicitnega) tipa, z možnima odgovoroma »da« ali »ne«, kot tudi odprtega tipa. Pri eksplicitnem tipu je imel intervjuvani na voljo podane odgovore, kjer je izbiral ustrezen odgovor, medtem ko je pri implicitnem tipu navedel ustrezen odgovor med nenavedenimi možnimi odgovori (Roulston 2008). Izvedeni intervjuji niso imeli natančno določenega poteka, vodili smo jih na podlagi teme, ki smo jo raziskovali, in nabora vprašanj, kar je značilnost polstrukturiranega intervjuja (Merriam 1998).

Izvedli smo 5 intervjujev med s turizmom povezanimi deležniki iz lokalnih, regionalnih in nacionalnih združenj ter organizacij, ki veljajo za izvedence s področja zasebnih turističnih nastanitev. Intervjuvali smo direktorja Turističnega združenja Portorož, direktorja turistične agencije Kompas Novo mesto, vodjo Turistične organizacije Koper, direktorja Lokalne turistične organizacije Turizem Podčetrtek in predstavnico vsebinskega digitalnega marketinga Slovenske turistične organizacije. Intervjuji so obsegali 9 vprašanj. Od tega so bila 4 vprašanja zaprtega in 5 vprašanj odprtega tipa. Med vprašanji zaprtega tipa sta bili dve vprašanji z možnim odgovorom »da« ali »ne« in dve vprašanji s podano ocenjevalno lestvico od 1 do 5 , kjer so intervjuvani ocenjevali pomembnost navedenih dejavnikov. Eno je bilo razdeljeno na sklope. Vsi intervjuvani so odgovarjali na ista vprašanja. Intervjuji so bili posredovani in izpolnjeni po elektronski pošti maja 2016. Intervjuvanci so odgovore posredovali pisno. Zagotovili smo jim anonimnost. 
Preglednica 1: Vprašanja izvedenskega intervjuja.

Table 1: Questions of the expert interview.

\begin{tabular}{|c|c|}
\hline 1. & Opišite najpogostejše vrste sobodajalstva na lokalni, regionalni in nacionalni ravni v Sloveniji. \\
\hline 2. & $\begin{array}{l}\text { Navedite, kateri dejavniki so po vašem mnenju trenutno najbolj kritični v Sloveniji na področju } \\
\text { sobodajalstva. Kateri so glavni problemi lastnikov zasebnih sob, družinskih hiš in malih hotelov v } \\
\text { Sloveniji? Opišite jih. }\end{array}$ \\
\hline 3. & $\begin{array}{l}\text { Ali potrebujejo sobodajalci visoko stopnjo znanja/vedenja o vodenju turistične dejavnosti v } \\
\text { Sloveniji? Da/Ne. Razložite. }\end{array}$ \\
\hline 4. & $\begin{array}{l}\text { Ali se udeležujete strokovnih usposabljanj in kako pogosto: } \\
\text { Da/Ne } \\
\text { Redno (v skupnem trajanju več kot } 3 \text { dni na leto) } \\
\text { Občasno (v skupnem trajanju } 1 \text { dan na leto) } \\
\text { Redko (v skupnem trajanju manj kot } 1 \text { dan na leto) }\end{array}$ \\
\hline 5. & $\begin{array}{l}\text { Prosimo, da navedete, katera od spodaj navedenih učnih področij bi bilo potrebno vključiti, da bi } \\
\text { sobodajalcem olajšali vsakodnevno delo (pri tem velja } 1 \text { - ni pomembno in } 5 \text { - zelo pomembno) in } \\
\text { zakaj: } \\
\text { Gostinstvo in kultura storitev } \\
\text { Načrtovanje s ciljem doseganja uspeha } \\
\text { Dnevno vodenje podjetja } \\
\text { Posodabljanje podjetja } \\
\text { Ustvarjalni in inovativni izdelki ter storitve } \\
\text { Promocija in učinkovita prodaja } \\
\text { Druga področja: prosimo, poimenujte jih in opišite ter ocenite }\end{array}$ \\
\hline 6. & $\begin{array}{l}\text { Prosim navedite, kateri so po vašem mnenju najbolj primerni načini za izobraževanje in } \\
\text { izpopolnjevanje sobodajalcev v Sloveniji (pri tem velja } 1 \text { - ni pomembno in } 5 \text { - zelo pomembno): } \\
\text { a. } \quad \text { Za pridobivanje idej in konceptov: } \\
\text { knjiga/učni listi } \\
\text { samoučenje } \\
\text { pod vodstvom inštruktorja } \\
\text { pod vodstvom inštruktorja s spletnim tečajem } \\
\text { s spletnimi razpravami v skupini } \\
\text { iz oči v oči s pogovori v skupini } \\
\text { interaktivno s pomočjo televizije/filma } \\
\text { s seminarji } \\
\text { drugo: prosimo, razložite in ocenite: }\end{array}$ \\
\hline
\end{tabular}




\begin{tabular}{|c|c|}
\hline & $\begin{array}{l}\text { b. Izobraževanje s pomočjo predstavitev in z opazovanjem ter vadbo spretnosti, tehnik in } \\
\text { miselnih procesov: } \\
\text { z razstavo } \\
\text { z izmenjavo dela/delovnih nalog } \\
\text { s študijo primera } \\
\text { z delovno skupino } \\
\text { s kritičnim mišljenjem } \\
\text { z igranjem vlog } \\
\text { s simulacijo/igro } \\
\text { drugo: prosimo, razložite in ocenite: } \\
\text { c. Za izboljšanje poglobljenega razumevanja: } \\
\text { z inštruiranjem } \\
\text { z delovnimi navodili } \\
\text { z mentorstvom } \\
\text { drugo: razložite in ocenite: } \\
\text { d. Za doseganje različnih učnih ciljev: } \\
\text { delavnica } \\
\text { drugo: razložite in ocenite: }\end{array}$ \\
\hline 7. & $\begin{array}{l}\text { Prosimo navedite zanimive prakse poklicnega izobraževanja in usposabljanja za sobodajalce v } \\
\text { Sloveniji? Prosimo, da navedete njihove podatke, kot je ime podjetja/naslov in/ali spletni naslov. }\end{array}$ \\
\hline 8. & Kaj bo po vašem mnenju v naslednjih 5 letih najbolj vplivalo na sobodajalce v Sloveniji? \\
\hline 9. & $\begin{array}{l}\text { Katera oblika usposabljanja ali učenja bo po vašem mnenju sobodajalcem najbolj pomagala } \\
\text { prilagoditi se na te spremembe? }\end{array}$ \\
\hline
\end{tabular}

Vir: Rooms to Vet, 2016.

S kodiranjem smo analizirali odgovore intervjuvancev na vprašanja odprtega tipa (vprašanja 1, 2, 7, 8 in 9), medtem ko smo odgovore na vprašanja zaprtega tipa samo opisno povzeli. Koda je v kvalitativnem raziskovanju navadno beseda ali kratka fraza, ki povzame/zajame bistvo določenega dela besedila ali vizualnega materiala (Saldaña, 2012). Uporabili smo induktivni pristop ali odprto kodiranje, kjer smo skozi branje odkrivali pomembne teme. Kodirali smo deskriptivno dvostopenjsko, tako da smo povzeli vsebino kvalitativnega teksta $\mathrm{z}$ identifikacijo topik. To je zmanjšalo količino podatkov in omogočilo povezavo razdrobljenih pomenov raziskovalne tematike v vsebinsko in pomensko zaključeni celoti, ki sta zadevali splošno problematiko sobodajalstva in potrebe po usposabljanju in izobraževanju. Kode 1. reda smo označili s številkami glede na pripadajoče besedilo in jih zapisali za odgovorom, kode 2. reda pa so nastale kot smiselna združitev kod 1. reda. Nato smo kode 2. reda smiselno uvrstili v kategorije. Na podlagi 
kodiranih podatkov in pomena kod smo prepoznavali vsebinsko in pomensko relevantne teme. Kode, ki smo jih ustvarili, smo nato interpretirali in rezultate strnili v razpravi.

\section{REZULTATI IN RAZPRAVA}

V preglednici 2 je prikazan primer kodiranja kvalitativnega zapisa vseh odgovorov na 1. vprašanje intervjuja $z$ dobesednim prepisom odgovora (zato se nekateri odgovori ali deli odgovorov dobesedno ali vsebinsko ponovijo) in kodami 1. in 2. reda ter kategorijo. Zaradi boljšse preglednosti smo posamezne odgovore postavili v oklepaje in jih označili z nadpisanimi številkami. Pod preglednico, zaradi dolgih odgovorov in pomanjkanja prostora $\mathrm{v}$ preglednici 3 , prikazujemo samo številko vprašanja, kode 1 . in 2 . reda ter kategorije. Sledijo analiza in interpretacija rezultatov kodiranja ter predstavitev, analiza in interpretacija odgovorov na vprašanja zaprtega tipa.

Preglednica 2: Primer kodiranja zapisov odgovorov.

Table 2: Example od coding.

\begin{tabular}{|c|c|c|c|c|}
\hline 1. Vprašanje & Dobeseden prepis odgovorov & Kode 1. reda & Kode 2. reda & Kategorije \\
\hline $\begin{array}{l}\text { Opišite } \\
\text { najpogostejše } \\
\text { vrste } \\
\text { sobodajalstva } \\
\text { na lokalni, } \\
\text { regionalni in } \\
\text { nacionalni ravni } \\
\text { v Sloveniji. }\end{array}$ & $\begin{array}{l}\left(\text { zasebni apartmaji) }{ }^{1},\right. \\
(\text { zasebni apartmaji, zasebne } \\
\text { sobe, zidanice, hiše, mali } \\
\text { hoteli) })^{2} \text {, (zasebni apartmaji } \\
\text { kot najpogostejša vrsta } \\
\text { sobodajalstva })^{3} \text {, (apartmaji, } \\
\text { majhni hoteli, zidanice), } \\
\text { (največji delež predstavljajo } \\
\text { zasebne sobe in apartmaji, v } \\
\text { zadnjem času se povečujejo tudi } \\
\text { apartmajske hiše, objekt, kjer so } \\
4 \text { ali več stanovanj, namensko } \\
\text { narejen za oddajanje kapacitet } \\
\text { v turistične namene, nekaj } \\
\text { manj je B\&B in pa t. i. "mini”, } \\
\text { hotelov, ki jih predvideva } \\
\text { PMTP, vendar zaenkrat to še } \\
\text { ni usklajeno s Pravilnikom o } \\
\text { kategorizaciji }{ }^{4} \text {. }\end{array}$ & $\begin{array}{l}1 \text { zasebni } \\
\text { apartmaji, sobe, } \\
\text { hiše, zidanice } \\
\text { in mali hoteli } \\
2 \text { najpogostejše } \\
\text { sobe in } \\
\text { apartmaji } \\
3 \text { povečujejo } \\
\text { se apartmajske } \\
\text { hiše } \\
4 \text { manj B\&B in } \\
\text { »mini hotelov« }\end{array}$ & $\begin{array}{l}\text { Zasebne oblike } \\
\text { nastanitev }\end{array}$ & $\begin{array}{l}\text { Tipologija } \\
\text { nastanitve }\end{array}$ \\
\hline
\end{tabular}




\section{Preglednica 3: Kodirani odgovori intervjuvancev.}

Table 3: Coded responses of the interviewees.

\begin{tabular}{|c|c|c|c|}
\hline Vprašanje & Kode 1. reda & Kode 2. reda & Kategorije \\
\hline 2. & 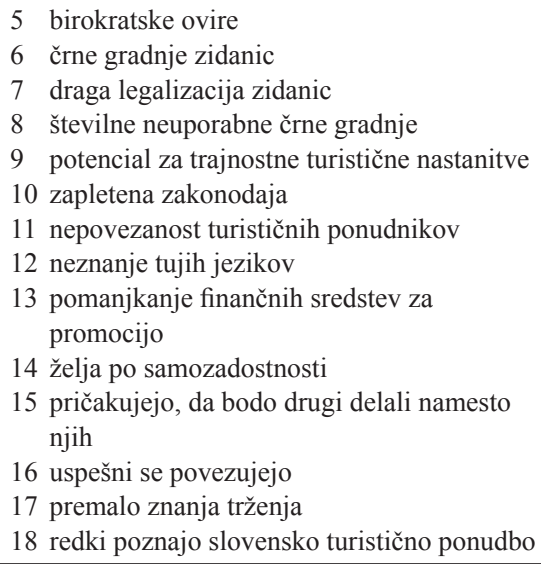 & $\begin{array}{l}\text { zakonodaja } \\
\text { individualizem } \\
\text { tuji jeziki } \\
\text { promocija } \\
\text { trženje } \\
\text { pričakovanja } \\
\text { nepoznavanje ponudbe }\end{array}$ & kritični dejavniki \\
\hline 7. & $\begin{array}{l}19 \text { podjetje Booking.com } \\
20 \text { dopolnilna dejavnost na kmetiji } \\
21 \text { KonektOn d.o.o., stičišče poslovnih ljudi } \\
22 \text { takih praks nismo zasledili } \\
23 \text { tržni seminarji na spletu }\end{array}$ & $\begin{array}{l}\text { izobraževanje iz } \\
\text { podjetništva } \\
\text { izobraževanje iz } \\
\text { dopolnilnih dejavnosti } \\
\text { na kmetiji } \\
\text { pomanjkanje } \\
\text { izobraževanj } \\
\text { spletno izobraževanje } \\
\text { o trženju }\end{array}$ & $\begin{array}{l}\text { izobraževanje in } \\
\text { usposabljanje }\end{array}$ \\
\hline 8. & $\begin{array}{l}24 \text { zakonodaja in internetni rezervacijski } \\
\text { sistemi } \\
25 \text { spletno trženje in ponudba namestitev v } \\
\text { obliki »sive ekonomije« } \\
26 \text { nepovezano delovanje in promocija ter } \\
\text { trženje } \\
27 \text { prezapletena in preobsežna zakonodaja in } \\
\text { predpisi } \\
28 \text { inovativnost } \\
29 \text { gostoljubje } \\
30 \text { stališča in ocene gostov } \\
31 \text { pojavnost na spletu in spletne rezervacije }\end{array}$ & $\begin{array}{l}\text { (zapletena) zakonodaja } \\
\text { spletne rezervacije } \\
\text { siva ekonomija } \\
\text { promocija in trženje } \\
\text { razvoj in inovacije } \\
\text { kakovost storitev } \\
\text { zadovoljstvo gostov }\end{array}$ & $\begin{array}{l}\text { vplivni dejavniki } \\
\text { za prihodnost }\end{array}$ \\
\hline
\end{tabular}




\begin{tabular}{|c|c|c|c|}
\hline Vprašanje & Kode 1. reda & Kode 2. reda & Kategorije \\
\hline 9. & $\begin{array}{l}32 \text { obvladovanje spletnih orodij } \\
33 \text { raziskovalno in problemsko naravnano } \\
\text { učenje s študijami primerov } \\
34 \text { praktične nove prodajne poti, ki jih } \\
\text { narekujejo trendi } \\
35 \text { predstavitve na spletnih rezervacijskih } \\
\text { portalih } \\
36 \text { inovativne storitve in delo z gosti } \\
37 \text { praktične delavnice in »turistične patrulje« } \\
\text { za nadzor kakovosti } \\
38 \text { spremljanje kakovosti ponudbe in storitev } \\
\text { ter odzivanje na kritike } \\
39 \text { sodelovanje ponudnikov v obliki druženja } \\
40 \text { učenje jezikov } \\
41 \text { konkretne delavnice in webinarji }\end{array}$ & $\begin{array}{l}\text { usvojitev spletnih } \\
\text { orodij } \\
\text { učenje s študijami } \\
\text { primerov } \\
\text { praktično učenje } \\
\text { trženja } \\
\text { spodbujanje } \\
\text { inovativnosti } \\
\text { praktične delavnice } \\
\text { učenje z izmenjavo } \\
\text { znanj in druženjem } \\
\text { ponudnikov } \\
\text { jezikovni tečaji } \\
\text { učenje z webinarji }\end{array}$ & $\begin{array}{l}\text { oblike } \\
\text { usposabljanja } \\
\text { ali učenja za } \\
\text { prihodnost }\end{array}$ \\
\hline
\end{tabular}

Pri prvem vprašanju, ki se je nanašalo na opis najpogostejše vrste sobodajalstva na lokalni, regionalni in nacionalni ravni v Sloveniji, so vsi intervjuvani izpostavili kot najpogostejšo obliko zasebne nastanitve sobe in apartmaje. Pri tem je eden od intervjuvanih izpostavil, da se povečuje število apartmajskih hiš, nekoliko manj pa je »mini hotelov«. Odgovori na drugo vprašanje, ki se je nanašalo na trenutno najbolj kritične dejavnike sobodajalstva in glavne probleme lastnikov zasebnih sob, družinskih hiš in malih hotelov, so bili raznoliki. Vsi intervjuvani so izpostavili zapleteno zakonodajo, birokratske ovire in nepovezanost turističnih ponudnikov. Poleg tega so izpostavili še črne gradnje zidanic, njihovo drago legalizacijo in neuporabnost ter neizkoriščen potencial za ureditev trajnostnih turističnih nastanitev, neznanje tujih jezikov med ponudniki nastanitev, pomanjkanje finančnih sredstev za promocijo, pretirano željo po samozadostnosti in pričakovanja, da bo nekdo drug opravil delo namesto njih. Izpostavili so, da le redki turistični ponudniki nastanitev poznajo slovensko turistično ponudbo in imajo premalo znanja s področja trženja, uspešni pa so tisti, ki se povezujejo. Odgovori na sedmo vprašanje, ki se je nanašalo na izpostavljanje primerov zanimivih praks poklicnega izobraževanja in usposabljanja za sobodajalce, kažejo, da je tovrstnih praks, osredotočenih na sobodajalstvo, v Sloveniji malo oziroma jih intervjuvani niso zaznali. Tako so vsi intervjuvani navedli le po en primer, in sicer: podjetje KonektOn d.o.o., ki se oglašuje kot stičišče poslovnih ljudi, ukvarja pa se s poslovnimi storitvami strateškega načrtovanja in managementa, izobraževanja v okviru dopolnilne dejavnosti na kmetiji, ki jih izvajajo razvojne agencije in Kmetijsko gozdarska zbornica Slovenije, in usposabljanje podjetja Booking.com. Eden od intervjuvanih je navedel še izobraževanje in usposabljanje s spletnimi tržnimi 
seminarji. Iz navedenih primerov zanimivih praks je razvidno, da je samo podjetje Booking.com usmerjeno v usposabljanje sobodajalcev za potrebe upravljanja s spletnimi rezervacijami, ki jih tudi sami ponujajo. Pri osmem vprašanju, ki je bilo osredotočeno na dejavnike, ki bodo v prihodnjih petih letih vplivali na sobodajalce v Sloveniji, smo dobili širok spekter raznolikih odgovorov. Tako so intervjuvani večkrat izpostavili preobsežno in prezapleteno zakonodajo in internetni rezervacijski sistem. Menijo, da bo vplivala tudi ponudba spletnega trženja v obliki »sive ekonomije«, na primer Airbnb in podobni portali, če tovrstno trženje ne bo regulirano. Med odgovori so bili izpostavljeni tudi nepovezano delovanje in promocija ter trženje, inovativnost, gostoljubje, stališča in ocene gostov ter pojavnost na spletu s spletnimi rezervacijami. Deveto vprašanje se je osredotočalo na oblike usposabljanja ali učenja, ki bodo sobodajalcem najbolj pomagale prilagoditi se na spremembe. Pri tem so odgovori intervjuvancev pokazali na različne oblike usposabljanja. Kot najsplošnejši odgovor je zaznati rabo spleta in pojavnost na spletu kot ključno obliko usposabljanja za različna specifična področja znanja, ki jim bo v prihodnje smiselno posvečati pozornost, da bi lahko sledili spremembam. Poleg omenjenega so izpostavili še druge oblike usposabljanja, kot je raziskovalno in problemsko naravnano učenje s študijami primerov, usposabljanje za iskanje praktičnih novih prodajnih poti, ki jih narekujejo trendi, usposabljanje za inovativne storitve in delo z gosti, usposabljanje s praktičnimi delavnicami in oblikovanjem »turističnih patrulj« za spremljanje kakovosti ponudbe in usposabljanje za nudenje storitev ter odzivanje na kritike, poleg tega pa še sodelovanje ponudnikov v obliki druženja, učenje jezikov in konkretne delavnice ter spletne seminarje.

S kodiranjem 2. reda smo najpogostejše vrste sobodajalstva združili v zasebne oblike nastanitev, ki smo jih uvrstili v kategorijo tipologija nastanitev. Najbolj kritične dejavnike sobodajalstva in glavne probleme lastnikov zasebnih sob, družinskih hiš in malih hotelov smo z nadaljnjim kodiranjem združili v zakonodajo, nepovezanost ponudnikov, tuje jezike, promocijo, trženje, pričakovanja in nepoznavanje ponudbe, kar smo uvrstili v kategorijo kritični dejavniki. Zanimive prakse poklicnega izobraževanja in usposabljanja za sobodajalce smo združili v izobraževanje iz podjetništva, dopolnilnih dejavnosti na kmetiji, pomanjkanje izobraževanj in spletno izobraževanje o trženju, kar smo uvrstili $\mathrm{v}$ kategorijo izobraževanje in usposabljanje. S kodiranjem 2. reda pri vprašanju, ki se je nanašalo na mnenje o dejavnikih, ki bodo v naslednjih 5 letih najbolj vplivali na sobodajalce, so z združevanjem nastale kode (zapletena) zakonodaja, spletne rezervacije, siva ekonomija, promocija in trženje, razvoj in inovacije, kakovost storitev in zadovoljstvo gostov, ki sodijo v kategorijo vplivnih dejavnikov za prihodnost. S kodiranjem 2. reda smo pri zadnjem vprašanju, ki se je nanašalo na oblike usposabljanja ali učenja, ki bodo $\mathrm{v}$ prihodnje sobodajalcem najbolj pomagale prilagoditi se na spremembe, oblikovali kode usvojitev spletnih orodij, učenje s študijami primerov, praktično učenje trženja, spodbujanje inovativnosti, praktične delavnice, učenje z izmenjavo znanj in druženjem ponudnikov, jezikovni tečaji in učenje z webinarji. Navedene kode 2. reda smo uvrstili v kategorijo oblike usposabljanja ali učenja za prihodnost.

$\mathrm{Z}$ analizo odgovorov na vprašanja zaprtega tipa (vprašanja 3, 4, 5 in 6) posvečamo največ pozornosti potrebam, področjem in načinom učenja in izobraževanja. Odgovore 
smo analizirali opisno, s povzemanjem vsebine odgovorov in izračunom povprečnih vrednosti. Na tretje vprašanje, ki se je nanašalo na obstoj potrebe sobodajalcev po visoki stopnji znanja/vedenja o vodenju turistične dejavnosti v Sloveniji (možen je bil odgovor »da« ali »ne«; odgovor je bilo treba razložiti), smo dobili zelo raznolike, nasprotujoče si odgovore. Dva intervjuvanca sta podala odgovor, da sobodajalci ne potrebujejo visoke stopnje znanj, medtem ko so ostali trije podali pritrdilen odgovor, torej da je visoka stopnja znanja o vodenju turistične dejavnosti potrebna. Intervjuvanec, ki je odgovoril, da slovenski sobodajalci ne potrebujejo visoke stopnje znanja o vodenju turistične dejavnosti, je razložil, da če »želijo uspešno voditi, morajo biti predvsem ustrežljivi in znati več jezikov in poznati aplikacije«, medtem ko je drugi, čigar stališče je ravno tako negativno, navedel, da »ne škodi, pomemben je občutek za turizem in ljudi, višja stopnja znanja lahko služi boljšemu gospodarjenju z dejavnostjo«. Preostali trije intervjuvanci so dali pritrdilen odgovor in razložili, da »morajo sobodajalci imeti kar visoka znanja o vodenju turistične dejavnosti, postopki so zelo zakomplicirani, neprijazni do preprostih ljudi in predvsem tistih, ki bi se radi ukvarjali s t. i. dopolnilno dejavnostjo in se iz takih ali drugačnih razlogov težko poglabljajo v našo, vsak dan spreminjajočo se, zakonodajo", da "za redno poslovanje potrebujejo dosti znanja o financah, tujih jezikih, računalniška znanja ... Za takšna znanja je potrebno izobraževanje« in poznati morajo »široko sliko slovenskega turizma in filozofijo, da se s svojo ponudbo lahko temu približajo, ne sme biti zadosti, da se zgolj oddajajo kapacitete, morajo imeti neko zgodbo, ki bi morala biti konsistentna s filozofijo zelene, aktivne in zdrave Slovenije«. Iz navedenega je razvidno, da stališče o potrebi po visoki stopnji znanja/vedenja ni enotno, čeprav med odgovori prevladujejo pozitivna stališča o potrebah po visoki stopnji znanja o vodenju turistične dejavnosti. Intervjuvanca, ki sta izpostavila, da visoka stopnja znanja ni potrebna, postavljata v ospredje osebne lastnosti, kot je ustrežljivost, in znanja, ki jih je mogoče praktično uporabljati, na primer znanje jezikov in raba aplikacij. Preostali trije intervjuvani, ki so podali pritrdilne odgovore, razlagajo, da je visoka stopnja znanja potrebna zaradi zapletene in spreminjajoče se zakonodaje, vsakodnevnega dela na področju financ, tujih jezikov in računalništva kot tudi zaradi nujnosti poznavanja turizma v Sloveniji nasploh, zlasti turistične filozofije, ki je usmerjena $\mathrm{v}$ aktivne in zelene oblike turizma, in posledično oblikovanja tovrstne turistične ponudbe.

$\mathrm{Na}$ četrto vprašanje, ki se je nanašalo na udeleževanje strokovnih usposabljanj in pogostost udeležbe, so vsi intervjuvani odgovorili pritrdilno. Štirje intervjuvani se občasno udeležujejo strokovnih usposabljanj, v skupnem trajanju 1 dan na leto, eden pa se jih udeležuje redno, v skupnem trajanju 3 dni na leto.

Na peto vprašanje, ki se je nanašalo na učna področja, ki bi jih bilo treba vključiti, da bi sobodajalcem olajšali vsakodnevno delo, so intervjuvanci odgovarjali tako, da so ocenili pomen posameznega področja ( 1 - ni pomembno in 5 -zelo pomembno) in pojasnili svojo oceno. Pojasnila ni dal nihče. Na voljo so imeli področja: gostinstvo in kultura storitev, načrtovanje s ciljem doseganja uspeha, dnevno vodenje podjetja, posodabljanje podjetja, ustvarjalni in inovativni izdelki ter storitve, promocija in učinkovita prodaja ter druga področja. Tako so ob pogledu na težave in nepredvidljive okoliščine ter na podlagi poznavanja dela najviše ocenili gostoljubnost in storitveno kulturo $(4,3)$, ki ji je sledilo 
načrtovanje vodenja podjetje $(4,1)$, medtem ko je vsakodnevno poslovanje podjetja prejelo najnižjo oceno $(3,6)$.

Šesto vprašanje se je nanašalo na najbolj primerne načine izobraževanja in izpopolnjevanja sobodajalcev in je bilo razdeljeno na naslednje sklope: pridobivanje idej in konceptov, izobraževanje s pomočjo predstavitev in z opazovanjem ter vadbo spretnosti, tehnik in miselnih procesov, za izboljšanje poglobljenega razumevanja in za doseganje različnih učnih ciljev. Intervjuvanci so ocenjevali ponujene načine izobraževanja. Med navedenimi načini v sklopu pridobivanje idej in konceptov so intervjuvani najviše ocenili kratke praktične delavnice (5), kar so sami napisali pod možnost »drugo«, in način iz oči v oči s pogovori v skupini $(4,4)$. Temu je sledilo samoučenje $(4,2)$, seminarji $(4)$, pod vodstvom inštruktorja $(3,6)$ in s spletnimi razpravami v skupini $(3,6)$. Kot najmanj pomemben način so ocenili način s knjigo/učnimi listi $(3,2)$ in interaktivni način s pomočjo televizije/ filma $(3,2)$. Med navedenimi načini v sklopu izobraževanje s pomočjo predstavitev in z opazovanjem ter vadbo spretnosti, tehnik in miselnih procesov so z najvišjo oceno ocenili izmenjavo dela/delovnih nalog $(4,6)$ in simulacijo/igro $(4,5)$. Temu je sledila študija primera $(4,4)$, igranje vlog $(3,8)$, delovna skupina $(3,8)$ in najnižje ocenjena načina kritično mišljenje $(3,6)$ in razstava (3). Med navedenimi načini za izboljšanje poglobljenega razumevanja so najvišjo oceno namenili inštruiranju $(3,6)$ in mentorstvu $(3,6)$, nekoliko nižje pa ocenili način $z$ delovnimi navodili $(3,4)$. V sklopu za doseganje različnih učnih ciljev so delavnice ocenili s 4,6. Pri tem v rubriki »drugo« niso navajali odgovorov.

$\mathrm{V}$ nadaljevanju dajemo odgovore na raziskovalna vprašanja. Rezultati kažejo, da znotraj tipologije nastanitve prevladujejo predvsem apartmaji in zasebne sobe. Kritičnih dejavnikov na področju sobodajalstva je več. Ti so področje zakonodaje, nepovezanost ponudnikov, pomanjkljivo znanje tujih jezikov, promocija, trženje, pričakovanja in nepoznavanje ponudbe. Zapletena zakonodaja sobodajalcem otežuje (vsakodnevno) delo, k temu pa bistveno pripomorejo tudi birokratske ovire, s katerimi se soočajo tako pri poslovodenju kot tudi investicijah. Pri tem velja omeniti, da področje sobodajalstva urejata dva zakona, zapletena zakonodaja in birokratske ovire pa marsikoga odvrnejo od možnosti zakonsko regularnega poslovanja, kar posledično pomeni poslovanje "na črno". Številni sobodajalci in turistični ponudniki so nepovezani, kar jim onemogoča skupen nastop na trgu in promocijo. Poleg omenjenega velja izpostaviti še črne gradnje zidanic in njihovo drago legalizacijo. Ti objekti predstavljajo neizkoriščen potencial za nastanitev. Zaradi navedenega so objekti prazni, nefunkcionalni in prepuščeni propadanju. Med sobodajalci je zaznati tudi neznanje tujih jezikov. Splošno znano je, da to najbolj velja za starejše generacije, ki niso imele v šolah v dovoljšni meri pouka angleščine ali drugih tujih jezikov. Kot kritični dejavnik so izpostavili še pomanjkanje finančnih sredstev za promocijo in pretirano željo po samozadostnosti. Slednje je tudi vzrok za nepovezanost sobodajalcev. Med sobodajalci obstaja tudi pričakovanje, da bo nekdo drug opravil delo namesto njih. Predstavljamo si, da imajo s tem v mislih predvsem občine in državne administrativne turistične urade, kot so turistično informacijski centri, lokalne turistične organizacije ali Slovenska turistična organizacija. Problematično je tudi področje nepoznavanja slovenske turistične ponudbe, kar je verjetno posledica nepovezanosti pa tudi nezadostnega izobraževanja. Tako imajo tudi nezadostna znanja s področja trženja. Zgoraj omenjeni 
kritični dejavniki, s katerimi se soočajo sobodajalci, predstavljajo osnovna področja za strokovna usposabljanja in izobraževanja sobodajalcev. Na podlagi odgovorov iz intervjujev lahko pritrdilno odgovorimo tudi na drugo zastavljeno raziskovalno vprašanje. Ugotavljamo, da večina intervjuvanih meni, da med sobodajalci obstaja potreba po visoki stopnji znanja/vedenja o vodenju turistične dejavnosti.

Med učnimi področji in načini izobraževanja in izpopolnjevanja sobodajalcev, ki bi jim olajšali vsakodnevno delo (na to sta se nanašali tretje in četrto raziskovalno vprašanje), so gostoljubnost in storitvena kultura ter načrtovanje vodenja podjetja. Del teh učnih področij so tudi v odgovorih intervjuvancev izpostavljeni kritični dejavniki, kot so zapletena zakonodaja, trženje in učenje jezikov. Najprimernejši načini so način $i z$ oči $v$ oči s pogovori v skupini in samoučenje ter seminarji. Najpomembnejša oblika pedagoškega dela se jim zdi izmenjava dela/delovnih nalog in simulacija/igra, medtem ko se jim zdita za izboljšanje poglobljenega razumevanja najpomembnejša inštruiranje in mentorstvo. Za doseganje različnih učnih ciljev so visoko ocenili delavnice.

V zvezi s petim raziskovalnim vprašanjem ugotavljamo, da je zanimivih praks usposabljanja ali učenja med sobodajalci v Sloveniji malo oziroma jih intervjuvani niso zaznali, z izjemo poslovodenja, financ in trženja ter dopolnilnih dejavnosti na kmetijah. Izobraževanja in usposabljanja, vezana na sobodajalstvo, izvaja samo podjetje Booking.com. $\mathrm{V}$ prihodnje bi bilo treba na področju učenja in usposabljanja dvigniti nivo znanja pri obvladovanju različnih spletnih orodij ter slediti trendom, kar bi povečalo prepoznavnost sobodajalcev in omogočilo enostavnejšo komunikacijo $z$ gosti. Pri tem so ena od možnosti spletni seminarji v obliki delavnic ali predavanj. Med drugimi oblikami so še raziskovalno in problemsko naravnano učenje s študijami primerov, usposabljanje za iskanje praktičnih novih prodajnih poti, ki jih narekujejo trendi, usposabljanje za inovativne storitve in delo z gosti, usposabljanje s praktičnimi delavnicami in oblikovanjem »turističnih patrulj« za spremljanje kakovosti ponudbe in usposabljanje za nudenje storitev ter odzivanje na kritike. Omenjeno bi prispevalo k izboljšanju kakovosti storitev.

\section{SKLEP}

V Evropi narašča delež zasebnih turističnih nastanitev. Narašča tudi delež turistov, ki se odločajo za nastanitev v zasebnih sobah, apartmajih ali stanovanjih. Statistični podatki kažejo, da se mnogi turisti odločajo za bivanje $\mathrm{v}$ zasebnih turističnih nastanitvah tudi $\mathrm{v}$ Sloveniji, zato velja področju zasebnih turističnih nastanitev nameniti več pozornosti.

V okviru evropskega projekta ROOMS to VET, v katerem so sodelovale države partnerice Hrvaška, Ciper, Grčija, Slovenija in Španija in katerega cilj je bil ohraniti in povečati konkurenčnost evropskega turističnega gospodarstva s podporo izpopolnjevanju in profesionalizaciji turističnih storitev, smo izvedli raziskavo potreb po izobraževanju med sobodajalci v Sloveniji, kar predstavlja osnovo za razvoj učnih gradiv ter nastanek brezplačne spletne platforme za usposabljanje. Ciljna skupina so bili s turizmom povezani izvedenci.

V pričujočem prispevku smo osvetlili problematiko sobodajalstva $v$ Sloveniji in predstavili rezultate raziskovanj v okviru projekta ROOMS to VET, kjer smo izpostavili 
splošno problematiko sobodajalstva v Sloveniji ter podrobneje raziskali področje izobraževanja med sobodajalci. Nasploh ugotavljamo, da predstavlja ključni splošni problem preobsežna in prezapletena zakonodaja, medtem ko je področje izobraževanja zapostavljeno, saj celovite ponudbe izobraževanj ni, četudi je na področju izobraževanja na državni ravni že opaziti premike, saj je bila nedavno sprejeta Strategija trajnostne rasti slovenskega turizma 2017-2021 (MGRT, 2017), v kateri je izobraževanje kadrov eno od ključnih področij. Ne glede na to bo v prihodnje treba več pozornosti posvetiti celovitemu izobraževanju sobodajalcev in slediti ciljem v omenjeni strategiji. Več pozornosti bo treba nameniti kritičnim dejavnikom, ki zadevajo splošno problematiko sobodajalstva in so jih intervjuvani izpostavili. To so področje prezapletene in preobsežne zakonodaje, nepovezanost ponudnikov, usvajanje tujih jezikov, promocija in trženje ter nepoznavanje ponudbe. Poleg omenjenega velja izpostaviti še črne gradnje zidanic ter drugih sekundarnih bivališč in možnost njihove legalizacije, saj sicer predstavljajo neizkoriščen potencial za legalno oddajanje nastanitev. Navedene kritične dejavnike bi bilo smotrno kot vsebino vključiti v izobraževalne programe in usposabljanja, s čimer bi sobodajalci usvojili manjkajoča znanja in tako izboljšali svoje storitve ter dvignili njihovo kakovost. Poleg tega velja posebno pozornost posvetiti tudi učnim področjem in načinom učenja, ki so jih intervjuvani izpostavili. Med učnimi področji bi jim najbolj koristilo poglobljeno učenje s področja gostoljubnosti in storitvene kulture ter načrtovanja vodenja podjetja, s čimer bi lahko povečali svoj ugled na trgu in vpeljali najsodobnejše prakse poslovanja. Posebej bi bilo treba izpostaviti tudi učenje tujih jezikov, kjer čutijo pomanjkanje znanja in jih bolj ali manj vsakodnevno uporabljajo pri delu z gosti. Pri tem se jim zdi najprimernejši način iz oči v oči s pogovori v skupini, kar pomeni vključevanje in sodelovanje vseh navzočih v skupini, kot tudi izmenjavo praktičnih primerov dobrih praks in reševanje konfliktnih situacij. Vse navedeno bi bilo smotrno izpeljati s pedagoško obliko dela, ki vključuje vse navzoče posameznike, to je z izmenjavo dela/delovnih nalog in simulacijo/igro. Za potrebe poglobljenega razumevanja bi bila za sobodajalce najpomembnejša inštruiranje in mentorstvo, kjer je v ospredju osebni stik z učiteljem/mentorjem, medtem ko bi različne učne cilje dosegali z delavnicami. Poleg omenjenega bi bilo treba dvigniti nivo znanja o različnih spletnih orodjih ter slediti trendom, kar bi v praksi za sobodajalce pomenilo usvojitev spletnih veščin na področju oglaševanja, trženja in komunikacije; poleg drugih, ki so jih intervjuvani uvrstili med kritične dejavnike.

Enovita obravnava splošne problematike sobodajalstva, kot tudi področja izobraževanja, bo zahtevala sodelovanje in kooperativnost med številnimi deležniki na različnih ravneh. Pri tem bodo pomembno vlogo imele nacionalna turistična organizacija (STO) ter lokalne (LTO) in občinske turistične organizacije, ki poleg formalnih izobraževalnih institucij (fakultet, visokih in višjih ter srednjih šol) in Gospodarske zbornice Slovenije lahko spodbudijo sobodajalce k izobraževanju, medtem ko bo na državni ravni treba posodobiti in poenostaviti zakonodajo. 


\section{Viri in literatura}

Alford, P., 1998. Positioning the destination product-can regional tourist boards learn from private sector practice? Journal of Travel \& Tourism Marketing, 7, 2, str. 53-68.

Cigale, D., Lampič, B., Potočnik-Slavič, I., 2013. Interrelations between tourism offer and tourism demand in the case of farm tourism in Slovenia. European Countryside, 2013, 5, 4, str. 339-355. DOI: 10.2478/euco-2013-0022.

Council of European Union, 2004. Draft Council conclusions on strengthening tourism by leveraging Europe's cultural, natural and maritime heritage - 11/2004 (15608/14). Bruselj, 9. str. URL: http://register.consilium.europa.eu/doc/srv?l=EN\&f=ST\%20 15608\%202014\%20INIT (citirano 5. 5. 2017).

Debeljak, P., 2009. Poslovni načrt podjetja Turist biro Piran. Diplomsko delo. Portorož, Univerza na Primorskem, Fakulteta za turistične študije - Turistica, 71 str.

European Commission, 2013. Entrepreneurship 2020 Action Plan. Bruselj, 33 str.

Eurostat, 2017. Tourism in Europe: first results for 2009 - Issue number 4/2010. Bruselj, 8 str. URL: http://ec.europa.eu/eurostat/documents/4168041/5945949/KS-QA-10-004EN.PDF/c2ccc6ce-0d83-4674-a7e8-202ea6f72012 (citirano 6. 5. 2017).

Hernández, J. M., Suárez-Vega, R., Santana-Jiménez, Y., 2016. The inter-relationship between rural and mass tourism: The case of Catalonia, Spain. Tourism Management, 54 , str. $43-57$.

Jurinčič, I., 2009. Nosilna zmogljivosti Slovenske Istre za turizem. Portorož, Fakulteta za turistične študije-Turistica, 221 str.

Jurinčič, I., Balažič, G., 2011. Development of tourist eco farms in protected natural areas in Slovenia : opportunities for sustainable tourism. V: Alvarez, M. D. (ur.). Advances in hospitality and tourism marketing and management: conference proceedings Istanbul, Turkey, June 19-24, 2011. Istanbul, Boğaziçi University, str. 572-576.

Merriam, S. B., 1998. Qualitative research and case study applications in education. San Francisco, Josey-Bass, 275 str.

MGRT (Ministrstvo za gospodarski razvoj in tehnologijo). 2017. Strategija trajnostne rasti slovenskega turizma 2017-2021. URL: http://www.mgrt.gov.si/fileadmin/mgrt.gov. si/pageuploads/Strategija_turizem_koncno_5.10.2017.pdf (citirano 10. 10. 2017).

Močnik, B., 2014. S sobodajalci na črno se nihče ne ukvarja. Delo, 29. julij 2014. URL: http:/www.delo.si/novice/slovenija/s-sobodajalci-na-crno-se-nihce-ne-ukvarja.html (citirano 8. 5. 2017).

Murn, B., Kocbek M., Krašovec M., 1992. Počitnice na kmetiji 92/93: vrnitev k naravi na sončni strani Alp: Slovenija. Ljubljana, Zadružna turistična agencija Vas.

Planinc, S., Planinc, T., Sedmak, G., 2015. Usvojitev informacijsko-komunikacijskih tehnologij med podjetniki v turizmu na slovenskem podeželju. V: Sedmak, G. in sod. (ur.). Spodbujanje ruralnega turizma = Poticanje ruralnog turizma. Koper: Založba Univerze na Primorskem; u Rijeci: Fakultet za menedžment u turizmu i ugostiteljstvu, Sveučilište, str. 177-191. URL: http://www.hippocampus.si/ISBN/978-961-6963-510/index.html (citirano 8. 5. 2017). 
Planinc, T., Sedmak, G., Planinc, S., Kociper, T., 2016. What knowledge is missing for more successful rural tourism? The evidence from Slovenia. V: Ravbar, D. et al. (ur.). European Union future perspectives : innovation entrepreneurship and economic policy, European Union future perspectives : innovation entrepreneurship and economic policy, conference, Pula, Croatia, 21-23 May 2015. Pula, Juraj Dobrila University of Pula, str. 295-303.

Rooms to Vet. 2016. Izvedenski intervjuji.

Roulston, K. J., 2008. Closed questions. V: Given, M. L. (ur.). The Sage encyclopedia of qualitative research methods. Los Angeles idr., Sage Publications, str. 83.

Saldaña, J., 2012. The coding manual for qualitative researchers. Los Angeles idr., Sage, 368 str.

Schensul, J. J., 2008. Key informant and local expert interviews. V: Given L. M. (ur.). The Sage encyclopedia of qualitative research methods. Los Angeles idr., Sage Publications, str. 523-524.

SURS (Statistični urad Republike Slovenije). 2016a. Prenočitvene zmogljivosti po vrstah občin in po vrstah nastanitvenih objektov, Slovenija, letno, v letu 2014. URL: http:// pxweb.stat.si/pxweb/Dialog/varval.asp?ma=2164502S\&ti=\&path=../Database/Ekonomsko/21_gostinstvo_turizem/02_21645_nastanitev_letno/\&lang=2 (citirano 10. 5. 2017).

SURS (Statistični urad Republike Slovenije). 2016b. Prihodi in prenočitve turistov po vrstah občin, po vrstah nastanitvenih objektov in po državah, Slovenija, letno, v letu 2014 URL: http://pxweb.stat.si/pxweb/Dialog/varval.asp?ma=2164505S\&ti=\&path=../ Database/Ekonomsko/21_gostinstvo_turizem/02_21645_nastanitev_letno/\&lang=2 (citirano 10. 5. 2017).

SURS (Statistični urad Republike Slovenije). 2017a. Metodološko pojasnilo - Nastanitvene zmogljivosti, prihodi in prenočitve. URL: http://www.stat.si/StatWeb/File/DocSysFile/7779 (citirano 30. 11. 2017).

SURS (Statistični urad Republike Slovenije). 2017b. Popis kmetijskih gospodarstev 2010. URL: http://pxweb.stat.si/pxweb/Database/Agriculture_2010/Agriculture_2010.asp (citirano 9. 5. 2017).

Pravilnik o kategorizaciji nastanitvenih obratov. 2008-2009. Uradni list RS, št. 62/08, $80 / 08,115 / 08$ in $72 / 09$.

Stanovanjski zakon. 2003. Uradni list RS, št. 69/03.

Pravilnik o minimalnih tehničnih pogojih in o minimalnem obsegu storitev za opravljanje gostinske dejavnosti. 2000-2008. Uradni list RS, št. 88/00, 114/04 in 52/08.

Zakon o gostinstvu. 2007. Uradni list RS, št. 93/07. 


\section{EDUCATIONAL NEEDS OF SMALL HOTEL AND NON-HOTEL PROVIDERS IN SLOVENIA}

\section{Summary}

Europe is the world's no. 1 tourist destination, with the highest density and diversity of tourist attractions, with $13 \%$ of all accommodations. Many tourists today opt for rooms, apartments or flats provided by smaller concerns - for instance, families with a few vacant spaces, rather than hotels. This is increasingly the case in Slovenia. According to data from the Statistical Office of the Republic of Slovenia (2016), 13,988 permanent beds in private accommodation (rented rooms, dwellings) facilities were registered in Slovenia in 2014. Statistics recorded that such small hotel and non-hotel providers' (SHNHP from here) accommodation facilities had 606,094 overnight stays in 2014, representing a $6.3 \%$ share of the total number of overnight stays in all accommodation units (Slovenia had a total of 9,590,642 overnight stays).

The article focuses on the findings of the project ROOMS to VET. The aim of the European project ROOMS to VET that included the partner countries Croatia, Cyprus, Greece, Slovenia and Spain, was to preserve and enhance the competitiveness of the European tourism industry by supporting the upgrading of tourist services among providers of SHNHP tourist accommodation, which was the basis for the development of teaching materials and the creation of a free online training platform. The target groups were tourism-related stakeholders from local, regional, national and European associations and organizations. The purpose of the paper is to explore the general issues between providers of SHNHP tourist accommodation and their educational needs. With the help of expert interviews, we detected particular problems, highlighted limitations and opportunities, and indicated solutions for more efficient and regulated development of this tourism sector.

SHNHP (15 beds or fewer) accommodations in Slovenia can be legally rented out in two ways. One is according to the Law on Catering from 2007 and the other is under the Law on Housing (Official Gazette of RS, no. 69/2003). One of the key problems are unregistered tourists. Jurinčič (2009) estimated the proportion of unregistered tourists in Slovenian Istria at 11,250 , or $50 \%$, on the basis of increased water consumption. Among the unregistered tourists who are consumers of water are considered daily visitors/swimmers, unregistered tourists in SHNHP rooms, holiday homes and other auxiliary/SHNHP facilities, relatives, acquaintances and seasonal owners of apartments and houses. The evasion of the payment of tourist tax and other municipal duties deprives communities of funding for a municipal infrastructure that may be overloaded during the season. This could have a significant impact on the quality of tourist services available to the registered tourists who perceived their destination as one with crowded roads and beaches, with somewhat limited water in dry periods, a lack of parking spaces, etc. We believe that it is necessary to inform SHNHP room renters about the consequences of illegal hiring of private accommodation capacities. But any education currently available is only for registered room renters, as others are not listed on the website of local tourism organizations and do not participate in trainings organized by various tourism stakeholders. There is of course no lack of opportunities for formal tourist education in Slovenia, but on the part of 
SHNHPs, there is less likelihood of a perceived need for tourist education, even if they do recognize problems they face. Our research goal was to obtain the answer to basic questions related to the problems perceived by providers of SHNHP tourist accommodations and specific issues related to their needs for training and education.

We derived the following research questions:

1. Which factors are the most critical in the field of renting SHNHP accommodations in Slovenia and why?

2. Do providers need a higher level of knowledge about tourism management?

3. What kind of learning fields would make their day-to-day work easier?

4. What are the most appropriate ways to educate and train SHNHP room renters?

5. What interesting VET practices for renters do they know of and what type of training or learning will most help them to adapt to the upcoming changes?

Answers were obtained through expert interviews that began with a handful of questions covering general topics. Characteristics of both structured and semi-structured interviews were used. Thus, the interviewees responded within the set content or thematic framework of closed questions, explicit or implicit type, with possible "yes" or "no" answers, as well as an open type (Roulston 2008). The interviews did not have a precise course; they were guided by the topic and the set of questions, which is a characteristic of a semi-structured interview (Merriam 1998). We conducted 5 interviews with tourismrelated stakeholders from local, regional and national associations that are experts in the field of SHNHP tourist accommodations. We interviewed the director of the Tourist Association of Portorož, the director of the tourist agency Kompas Novo mesto, the head of the Tourism Organization of Koper, the director of the Tourist Association Podčetrtek and the representative of digital marketing of the Slovenian Tourist Board. The interviews included 9 questions, 4 closed and 5 open-ended questions. Among the questions of the closed type, there were two questions with the possible answer "yes" or "no" and two questions with a given rating scale of 1-5, where the interviewees assessed the importance of listed factors. Interviews were submitted and completed in May 2016 by e-mail. The interviewees sent written answers.

We analyzed the answers of open-ended questions by coding, while we descriptively summarized the answers to closed questions. We coded descriptively so that we summarized the content of the qualitative text with the identification of the topics. The code in a qualitative study is usually a word or a short phrase that summarizes/captures the essence of a particular piece of text or visual material (Saldaña, 2012).

We found that there are several critical factors in the field of SHNHP room renting that cause problems for renters. Key issues are complex legislation, bureaucratic obstacles, provider's incoherence, (low) foreign language skills and marketing. We also came to the conclusion that renting rooms requires a high degree of knowledge, training and education. Necessary training of SHNHPs would be most feasible through short practical workshops, and in the form of pedagogical work involving the exchange of tasks. In order to improve in-depth understanding, the most appropriate form would be coaching and mentoring. 
Generally, we found that the area of education of SHNHP tourist providers is neglected. More should be done to offer education for SHNHPs. At the national level there are already noticeable shifts in the recently adopted Strategy of sustainable growth of Slovenian tourism 2017-2021 in which education and training represent one of the key areas. In this regard, the National Tourism Organization (STO), the local (LTO) and municipal tourist organizations, formal educational institutions the Chamber of Commerce and Industry of Slovenia, all need to address this issue. At the state level modernization and simplification of the legislation is necessary.

At the same time, so as not to appear naïve, we must address the issue purely from the economic points of view of those SHNHP renters, who, as far as they now know, have nothing to gain by coming forward to take on the responsibilities of acknowledged tourism providers.

(Translated by Rick Harsch) 